\title{
Bcl-2 expression predicts sensitivity to chemotherapy in breast cancer: a systematic review and meta-analysis
}

Dong Yang ${ }^{1+}$, Min-Bin Chen ${ }^{2+}$, Li-Qiang Wang ${ }^{2}$, Lan Yang ${ }^{3}$, Chao-Ying Liü ${ }^{4^{*}}$ and Pei-Hua Lu ${ }^{4^{*}}$

\begin{abstract}
Background: Numerous studies have yielded inconclusive results regarding the relationship between anti-apoptotic protein $\mathrm{Bcl}-2$ expression and the sensitivity to chemotherapy in the patients with breast cancer. The purpose of the current study was therefore to elaborate their relationship.

Methods, findings: A total of 23 previously published eligible studies involving 2,467 cases were identified and included in this meta-analysis. Negative Bcl-2 expression was associated with good chemotherapy response in breast cancer patients (total objective response [OR]: risk ratio $[R R]=1.16,95 \%$ confidence interval $[\mathrm{Cl}]=1.02-1.32, p=0.026$; total complete response [CR]: $R R=1.67,95 \% C l=1.24-2.24, p=0.001$; pathological $C R: R R=1.92,95 \% C l=1.38-2.69, p<$ 0.001). In further stratified analyses, this association remained for sub-groups of response in neoadjuvant chemotherapy setting, especially pathological CR. Besides, negative $\mathrm{BCl}-2$ expression was significantly associated with good OR and pathological CR in anthracycline-based chemotherapy subgroup. Furthermore, there were significant links between negative $\mathrm{BCl}-2$ expression and taxane-based chemotherapy with pathological $\mathrm{CR}$, but not $\mathrm{OR}$.
\end{abstract}

Conclusion: The results of the present meta-analysis suggest that $\mathrm{BCl}-2$ expression is a predictive factor for chemotherapy sensitivity in breast cancer patients. They could also potentially benefit further clinical treatment for breast cancers.

Keywords: BCl-2, Breast cancer, Chemotherapy, Response

\section{Introduction}

Breast cancer remains a major medical problem in women despite of dramatic advances in clinical and research have been achieved in the last three decades. Chemotherapies including neoadjuvant chemotherapy, adjuvant chemotherapy, and systemic chemotherapy, are widely used in breast cancer treatment. However, whether a patient responds to chemotherapy remains unpredictable, a proportion of patients fail to respond to chemotherapy, or even progress during therapy. Because the information on the drug sensitivity of tumors is often unknown before treatment initiation, many patients are treated, but only a few are benefited. Thus, predicting how well a patient will

\footnotetext{
*Correspondence: liucy@wuxiph.com; Iphty1_1@163.com

${ }^{\dagger}$ Equal contributors

${ }^{4}$ Department of Medical Oncology, Wuxi People's Hospital affiliated to Nanjing Medical University, 299 Qingyang Road, Wuxi City, Jiangsu Province 214023, China

Full list of author information is available at the end of the article
}

respond to chemotherapy and the risk of relapse is essential in deciding the best treatment option for each individual patient. Multiple biomarkers with potential predictive value have been evaluated in breast cancer, which may be useful for identifying those patients who would benefit from certain chemotherapy [1].

Conventional chemotherapeutic agents generally kill via the mitochondrial apoptotic pathway [2]. Mitochondrial priming is controlled by the Bcl-2 family of proteins [2,3]. This family consists of both pro-apoptotic and anti-apoptotic members. If pro-apoptotic members overwhelm the anti-apoptotic members, the threshold of death is crossed and the cell dies through apoptosis. The ability of Bcl-2 to prevent apoptosis is antagonized by the pro-apoptotic members of the Bcl-2 family [4]. Cytotoxic chemo-agents that promote apoptosis through DNA damage or microtubule disruption can be inhibited by 
Bcl-2 expression [5]. An in vitro study showed that overexpression of $\mathrm{Bcl}-2$ increased the resistance of MCF-7 cells to doxorubicin, and this resistance was positively correlated with Bcl-2expression level of individual MCF/ Bcl-2 clones [6]. Studies demonstrated that Bcl2 inhibition through targeted-RNAi knockdown or Bcl-2 antagonist (ABT-737) increased cellular response to daunorubicin, etoposide, and mitoxantrone in the THP-1 and OCI-AML3 cell lines [7], and targeting of the proteins $\mathrm{Bcl}-2$ and $\mathrm{Bcl}-\mathrm{xL}$ with $\mathrm{ABT}-737$ may reverse the acquired radioresistance of MDA-MB-231R cells in vitro and in vivo [8].

Although there are now a large number of studies focusing on Bcl-2 expression in breast cancers, however, the association between its expression and chemosensitivity was not conclusive, mostly due to the small sample size of each study. We therefore performed a meta-analysis of the value of $\mathrm{Bcl}-2$ expression for predicting sensitivity to chemotherapy in breast cancer.

\section{Materials and methods Publication search}

PubMed, Embase, and Web of Science databases were searched (up to September 20, 2013) using the search terms: 'Bcl-2,' 'BCL2', 'bcl', 'bcl"', 'B-cell CLL/lymphoma 2', 'chemotherapy' and 'breast cancer'. All potentially eligible studies were retrieved and their bibliographies were carefully scanned to identify other eligible studies. Additional studies were identified by a hand search of the references cited in the original studies. When multiple studies of the same patient population were identified, we included the published report with the largest sample size. Only studies published in English were included in this meta-analysis.

\section{Inclusion and exclusion criteria}

Studies included in this meta-analysis had to meet all of the following criteria: (a) evaluation of Bcl-2 expression for predicting the response to chemotherapy in breast cancer, (b) studies with data on initial treatment, excluding studies

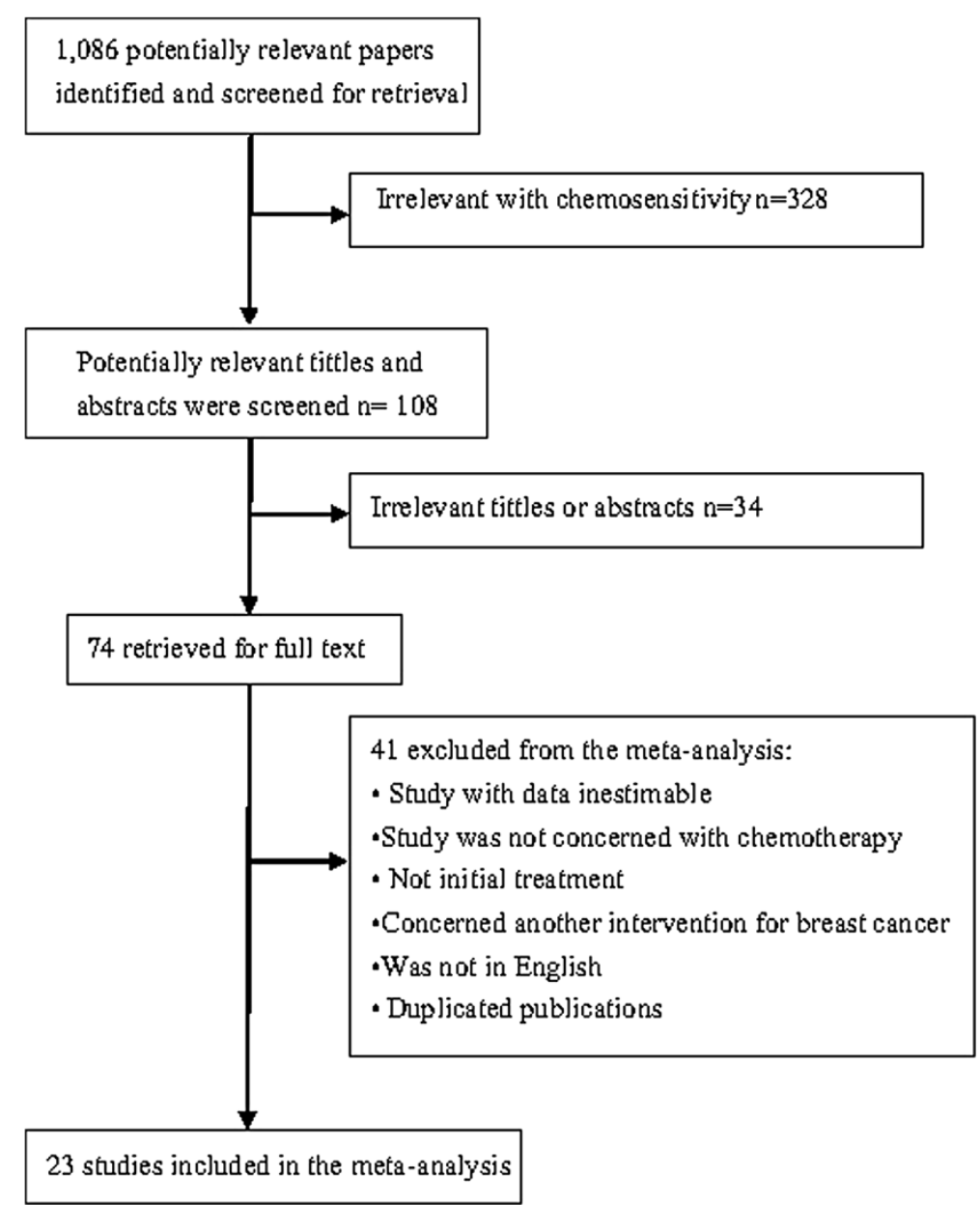

Figure 1 Improving the quality of reports of meta-analyses of randomized controlled trials; the Quality of Reporting of Meta-Analyses (QUOROM) statement flow diagram. 
Table 1 Characteristics of studies included in the meta-analysis

\begin{tabular}{|c|c|c|c|c|c|c|c|c|c|}
\hline Author & Year & Country & Case & Disease stage & Method & Treatment & Detection & $\begin{array}{l}\text { Provided information } \\
\text { on cutoff value }\end{array}$ & Response \\
\hline Grim [12] & 2012 & $\begin{array}{l}\text { Czech } \\
\text { Republic }\end{array}$ & 61 & locally advanced & $\mathrm{NCT}$ & TAC & $\mathrm{IHC}$ & $\geq 10 \%$ stained cell & Pathological CR \\
\hline Chen [13] & 2012 & China & 91 & $\|-\||| C$ & NCT & $\mathrm{PCb}$ & $\mathrm{IHC}$ & $\geq 10 \%$ stained cell & Pathological CR \\
\hline Petrarca [14] & 2011 & Brazil & 45 & $\|-1\|$ & NCT & $A C-T$ & $\mathrm{IHC}$ & $>5$ (expression score range, $0-15$ ) & Pathological CR \\
\hline von Minckwitz [15] & 2008 & Germany & 196 & $\mathrm{~T}_{2-3}(\geq 3 \mathrm{~cm}) \mathrm{N}_{\mathrm{o-2}} \mathrm{MO}$ & NCT & $\begin{array}{l}\text { ddAT with or } \\
\text { without tamoxifen }\end{array}$ & $\mathrm{IHC}$ & $>1+$ (range $0-3+)$ & Pathological CR \\
\hline Vargas-Roig [16] & 2008 & Argentina & 110 & $\mathrm{~T}_{2-4} \mathrm{~N}_{0-1} \mathrm{MO}$ & NCT & $\mathrm{FAC/FEC} \mathrm{or} \mathrm{D/E}$ & $\mathrm{IHC}$ & $>33 \%$ of stained cells & $P R+C R$ \\
\hline Keam [17] & 2007 & Korea, & 145 & II-III & NCT & docetaxel + doxorubicin & $\mathrm{IHC}$ & $\geq 10 \%$ stained cell & OR \\
\hline Tiezzi [18] & 2006 & Brazil & 44 & locally advanced & $\mathrm{NCT}$ & FEC or DE & $\mathrm{IHC}$ & $\geq 5$ (range $0-7$ ) & OR \\
\hline Noguchi [19] & 2006 & Japan & 63 & NR & NR & Docetaxel & $\mathrm{IHC}$ & NR & OR \\
\hline Mieog [20] & 2006 & Netherlands & 107 & $T_{1-4}$ & NCT & FEC & $\mathrm{IHC}$ & $\begin{array}{l}\text { staining } \geq 3 \text { indicates } \\
\text { positive status }\end{array}$ & $\begin{array}{l}\text { Pathological } \\
\mathrm{CR}+\mathrm{OR}\end{array}$ \\
\hline $\begin{array}{l}\text { Fernandez- } \\
\text { Sanchez [21] }\end{array}$ & 2006 & Mexico & 40 & $\|\mathrm{~B}-\| \mathrm{B}$ & NCT & FAC & $\mathrm{IHC}$ & $\geq 10 \%$ stained cell & OR \\
\hline Prisack [22] & 2005 & Germany & 517 & locally advanced & NCT & $\mathrm{EC} \pm \mathrm{RT}$ & $\mathrm{IHC}$ & score $\geq 100$ & Pathological CR \\
\hline Kim [23] & 2005 & Japan & 63 & $\begin{array}{l}\text { tumor }>3 \mathrm{~cm} \text { and axillary } \\
\text { lymph node involvement }\end{array}$ & NCT & docetaxel & $\mathrm{IHC}$ & Grades 2 and 3 & $\begin{array}{l}\text { Pathologic } \\
\text { responders }\end{array}$ \\
\hline Buchholz [24] & 2005 & USA & 82 & II-IV & NCT & FAC & $\mathrm{IHC}$ & $\begin{array}{l}\text { presence of any cytoplasmic } \\
\text { staining of the tumor cell cytoplasm }\end{array}$ & Pathological CR \\
\hline Pusztai [25] & 2004 & USA & 28 & $\|A-\| B$ & NCT & FAC & $\mathrm{IHC}$ & any signal in neoplastic cells & Pathological CR \\
\hline Ogston [26] & 2004 & UK & 104 & large and locally advanced & $\mathrm{NCT}$ & $\begin{array}{l}\text { anthracycline-based } \pm \\
\text { docetaxel }\end{array}$ & $\mathrm{IHC}$ & $\geq 10 \%$ stained cell & $\begin{array}{l}\text { Good pathological } \\
\text { response }\end{array}$ \\
\hline Mathieu [27] & 2004 & France & 129 & $\mathrm{~T}_{2}>3 \mathrm{~cm}-\mathrm{T}_{4}$ & NCT & AVCMF or FAC/FEC & $\mathrm{IHC}$ & $\geq 10 \%$ stained cell & Pathological CR \\
\hline Stearns [28] & 2003 & USA & 29 & $T_{3}$ or $T_{4}$ & NCT & $A-T$ & $\mathrm{IHC}$ & $\begin{array}{l}\text { Cytoplasmic staining.Intensity } \\
\text { and } \% \text { positive cells. } \\
\text { Score } \geq 6=\text { positive }\end{array}$ & Pathological CR \\
\hline Geisler [29] & 2001 & Norway & 94 & $\mathrm{~T}_{3} / \mathrm{T}_{4}$ and/or $\mathrm{N}_{2}$ tumors & NCT and first-line & EC & $\mathrm{IHC}$ & index $\geq 6$ & $\mathrm{PR}$ \\
\hline Pernick [30] & 2000 & USA & 34 & $\| B$ or II & $\mathrm{NCT}$ & $\begin{array}{l}\text { adriamycin }(n=32) \text {, taxol } \\
(n=7) \text {, or taxotere }(n=7)\end{array}$ & $\mathrm{IHC}$ & $\begin{array}{l}5 \% \text { or more tumor } \\
\text { cells stained. }\end{array}$ & $C R$ \\
\hline Bottini [31] & 2000 & Italy & 157 & $\mathrm{~T}_{2-4} \mathrm{~N}_{0-1} \mathrm{MO}$ & NCT & $\begin{array}{l}C M F \pm \text { tamoxifen } \\
\text { or epirubicin }\end{array}$ & $\mathrm{IHC}$ & $\geq 20 \%$ stained cell & $C R+O R$ \\
\hline
\end{tabular}


Table 1 Characteristics of studies included in the meta-analysis (Continued)

\begin{tabular}{|c|c|c|c|c|c|c|c|c|c|}
\hline Nole [32] & 1999 & Italy & 39 & $T_{1}-T_{3}$ & NCT & FLN & $\mathrm{IHC}$ & $>10 \%$ stained cell & OR \\
\hline Colleoni [33] & 1999 & Italy & 73 & $\mathrm{~T}_{2}-\mathrm{T}_{3}, \mathrm{~N}_{0-2}$ & NCT & FLN or $A C$ & $\mathrm{IHC}$ & $>10 \%$ stained cell & OR \\
\hline Makris [34] & 1997 & UK & 90 & $\begin{array}{l}T_{1}(N=23), T_{2}(n=58), T_{3} / T_{4}(N= \\
9)\end{array}$ & NCT & $\begin{array}{l}\text { mitozantrone, methotrexate } \\
\text { and tamoxifen }\end{array}$ & $\mathrm{IHC}$ & NR & OR \\
\hline
\end{tabular}

NCT, neoadjuvant chemotherapy; IHC, immunohistochemistry; A, doxorubicin; E, epirubicin; D, docetaxel; P, paclitaxel; F, 5-fluorouracil; EC, epirubicin and cyclophosphamide; FEC, 5-fluorouracil, epirubicin, and cyclophosphamide; FAC, 5-fluorouracil, doxorubicin, and cyclophosphamide: CMF, cyclophosphamide, mitomycin C and 5-fluorouracil; AVCMF, doxorubicin, vincristine, cyclophosphamide, methotrexate and 5-fluorouracil P-

FEC sequential palitaxel and 5 FU/ pirubicin/cyclophosphamide; FUMI weekly) doxorubicin and docetaxel; FLN, 5-fluorouracil + folinic acid + vinorelbine; D and MF docetaxel; docetaxel to sequential methotrexate and 5-fluorouracil;NR, not reported. 
reporting relapsed disease or second line therapy, (c) described therapeutic response, (d) retrospective or prospective cohort study, (e) inclusion of sufficient data to allow the estimation of a risk ratio (RR) with $95 \%$ confidence intervals $(95 \% \mathrm{CI})$, and (f) studies published in English. Letters to the editor, reviews, and articles published in books, or papers published in a language other than English were excluded.

\section{Data extraction and definitions}

According to the inclusion criteria listed above, the following data were extracted for each study: the first author's surname, publication year, country of origin, number of patients analyzed, types of measurement, and the treatment. Data on the main outcomes were entered in tables showing the response to chemotherapy with respect to $\mathrm{Bcl}-2$ expression. Information was carefully and independently extracted from all eligible publications by two of the authors (Yang and Chen). Any disagreement between the researchers was resolved by discussions until a consensus was reached. If they failed to reach a consensus, a third investigator $(\mathrm{Lu})$ was consulted to resolve the dispute.

Response was defined as complete response $(\mathrm{CR})$, partial response (PR), or objective response (OR) $(\mathrm{OR}=\mathrm{CR}+\mathrm{PR})$. Non-response was defined as stable disease (SD) or progressive disease (PD), according to WHO criteria [9] or RECIST (Response Evaluation Criteria in Solid Tumors) criteria [10].

\section{Statistical analysis}

RR with 95\% CIs was used to estimate the association between $\mathrm{Bcl}-2$ expression and response to chemotherapy in breast cancer patients. Subgroup analyses were performed to evaluate the effects of neoadjuvant chemotherapy and different treatment regimens (anthracycline-based and taxane-based). Heterogeneity assumption was checked

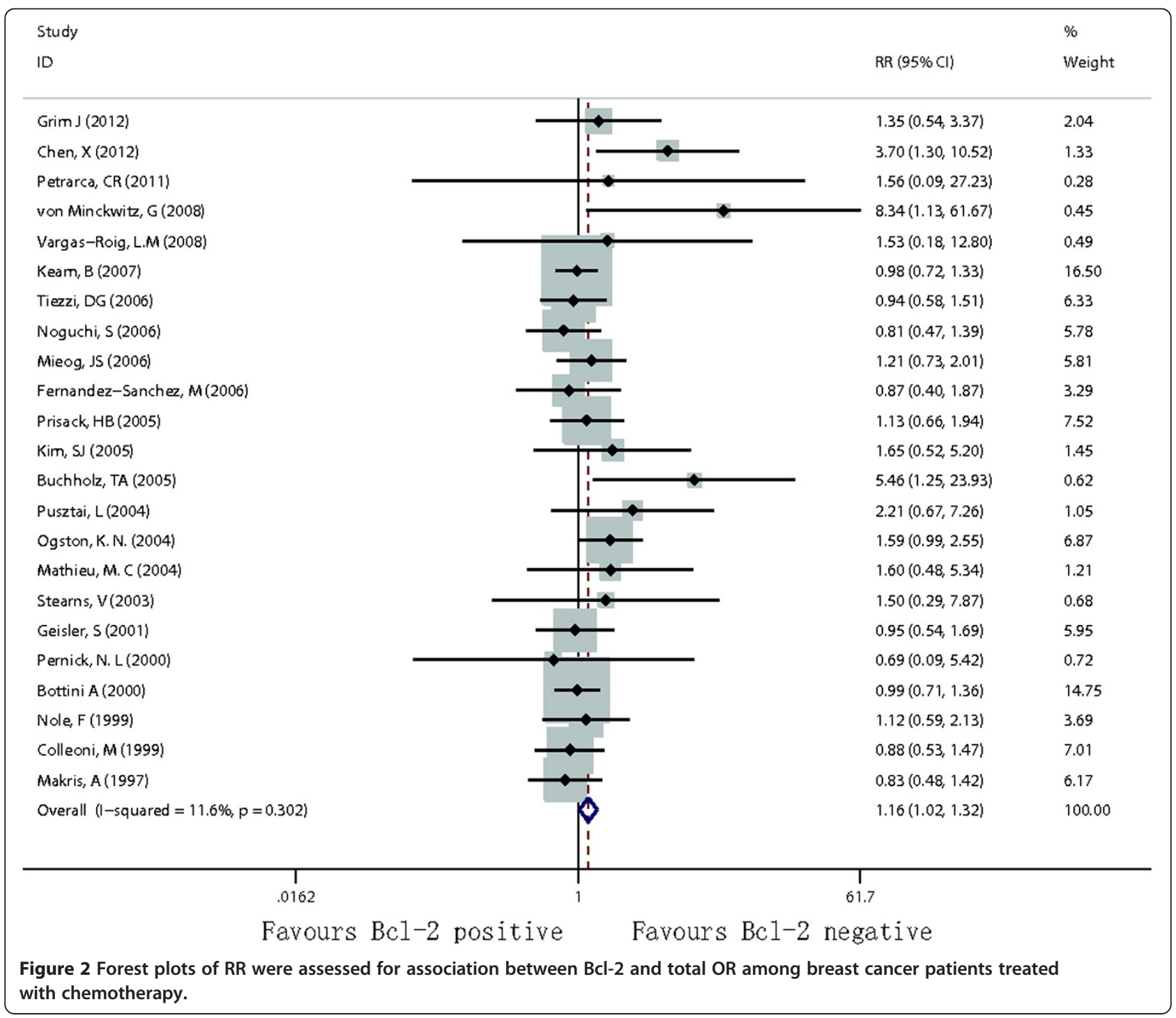


using the $Q$ test, and a p value $>0.10$ indicated a lack of heterogeneity among studies. We also quantified the effect of heterogeneity using $I^{2}=100 \% \times(\mathrm{Q}-\mathrm{df}) / \mathrm{Q} \cdot I^{2}$ values of $<25 \%$ may be considered "low", values of about $50 \%$ may be considered "moderate" and values of $>75 \%$ maybe considered "high" [11]. In the absence of statistical heterogeneity, a fixed effects model was employed (the Mantel-Haenszel method). If heterogeneity was present, a random effects model (DerSimonian-Laird method) was used to account for inter-study heterogeneity. Funnel plots and the Egger's test were employed to estimate the possible publication bias. We also performed sensitivity analysis by omitting each study or specific studies to find potential outliers. Statistical analyses were conducted using Stata (version SE/10; StataCorp, College Station, TX). p values for all comparisons were two-tailed and statistical significance was defined as $\mathrm{p}<0.05$ for all tests, except those for heterogeneity.

\section{Results}

\section{Eligible studies}

A total of 1,086 articles were retrieved by a literature search of the PubMed, Embase, and Web of Science databases, using different combinations of key terms. As indicated in the search flow diagram (Figure 1), 23 studies reported at least one of the outcomes of interest and were included in this meta-analysis [12-34]. The main features of these eligible studies are summarized in Table 1 . The sample sizes in all the eligible studies ranged from $28-517$ patients (median $=90$ patients, mean $=107$ patients, standard deviation
[SD] =107). Overall, the eligible studies included a total of 2,467 patients. Nineteen of the studies were conducted in European or North American populations with mixed but mostly white participants (2,105 patients), whereas four were conducted in East Asian populations (362 patients).Data related to patients treated by neoadjuvant chemotherapy comprised 19 of the 23 breast cancer trials. Immunohistochemistry (IHC) techniques were used in all the trials to detect the expression of Bcl-2 protein. Various antibodies were used to assess Bcl-2 expression, and the cutoff in the number of positive cells defining a tumor with Bcl- 2 overexpression varies from 5\% to 50\%, more than $10 \%$ for most studies (Table 1 ).

\section{Evidence synthesis}

Among the studies dealing with breast cancer patients with chemotherapy response, twenty-three studies involving 2,467 patients contributed to data on total OR (clinical $\mathrm{OR}+$ pathological OR). Negative Bcl-2 expression was significantly associated with improved total OR among patients with chemotherapy $(\mathrm{RR}=1.16$; $95 \% \mathrm{CI}=1.02-1.32$; $\mathrm{p}=0.026$, Figure 2). Twelve studies involving 1,602 patients contributed to data on $\mathrm{CR}$ (pathological CR + clinical CR). Negative Bcl-2 expression was significantly associated with improved CR ( $R R=1.67 ; 95 \% C I=1.24-2.24 ; \mathrm{p}=0.001)$. Ten studies involving 1,285 patients contributed to data on total pathological CR. In fact, all these patients received neoadjuvant chemotherapy. Negative Bcl-2 expression was significantly associated with improved pathological CR $(\mathrm{RR}=1.92 ; 95 \% \mathrm{CI}=1.38-2.69 ; \mathrm{p}<0.001)$.

Table 2 Risk ratio for the association between $\mathrm{Bcl}-2$ expression and response to chemotherapy

\begin{tabular}{|c|c|c|c|c|c|c|}
\hline \multirow[t]{2}{*}{ Analysis } & \multirow[t]{2}{*}{$\mathbf{N}$} & \multirow[t]{2}{*}{ References } & \multirow[b]{2}{*}{ RR $(95 \% \mathrm{Cl})$} & \multirow[b]{2}{*}{$P$} & \multicolumn{2}{|c|}{ Heterogeneity } \\
\hline & & & & & $I^{2}(\%)$ & $P h$ \\
\hline \multicolumn{7}{|l|}{ All studies } \\
\hline OR & 23 & {$[12-34]$} & $1.16(1.02-1.32)$ & $0.026^{*}$ & 11.6 & 0.502 \\
\hline$C R$ & 12 & {$[12-15,20,22,24,25,27,28,30,31]$} & $1.67(1.24-2.24)$ & $0.001^{*}$ & 15.8 & 0.289 \\
\hline $\begin{array}{l}\text { Pathological CR } \\
\end{array}$ & 10 & {$[12-15,20,22,24,25,27,28]$} & $1.92(1.38-2.69)$ & $<0.001^{*}$ & 10.9 & 0.342 \\
\hline \multicolumn{7}{|l|}{ Response to NCT } \\
\hline OR & 19 & {$[12-18,20-22,24-26,28,30-34]$} & $1.19(1.04-1.37)$ & $0.014^{*}$ & 17.7 & 0.234 \\
\hline$\overline{C R}$ & 12 & {$[12-15,20,22,24,25,27,28,30,31]$} & $1.67(1.24-2.24)$ & $0.001^{*}$ & 15.8 & 0.289 \\
\hline Pathological CR & 10 & {$[12-15,20,22,24,25,27,28]$} & $1.92(1.38-2.69)$ & $<0.001^{*}$ & 10.9 & 0.342 \\
\hline \multicolumn{7}{|c|}{ Response to anthracycline-based } \\
\hline OR & 15 & {$[12,14-22,24-29]$} & $1.20(1.01-1.43)$ & $0.034^{*}$ & 15.5 & 0.280 \\
\hline Pathological CR & 9 & {$[12,14,15,20,22,24,25,27,28]$} & $1.76(1.24-2.51)$ & $0.002^{*}$ & 0.0 & 0.452 \\
\hline \multicolumn{7}{|c|}{ Response to docetaxel-based } \\
\hline $\mathrm{OR}$ & 8 & {$[12-15,17,19,23,28]$} & $1.37(0.88-2.14)$ & $0.160^{\#}$ & 46.3 & 0.071 \\
\hline Pathological CR & 4 & {$[12-14,28]$} & $2.11(1.14-3.88)$ & $0.017^{*}$ & 0.0 & 0.525 \\
\hline
\end{tabular}

$\mathrm{N}$, number of studies; Ph, p value of Q-test for heterogeneity.

*The pooled RR was calculated using a fixed-effects model (the Mantel-Haenszel method) according to the heterogeneity.

\#The pooled RR was calculated using a random-effects model (the DerSimonian and Laird method) according to the heterogeneity.

Subgroup analysis was performed when there were at least two studies in each subgroup. 


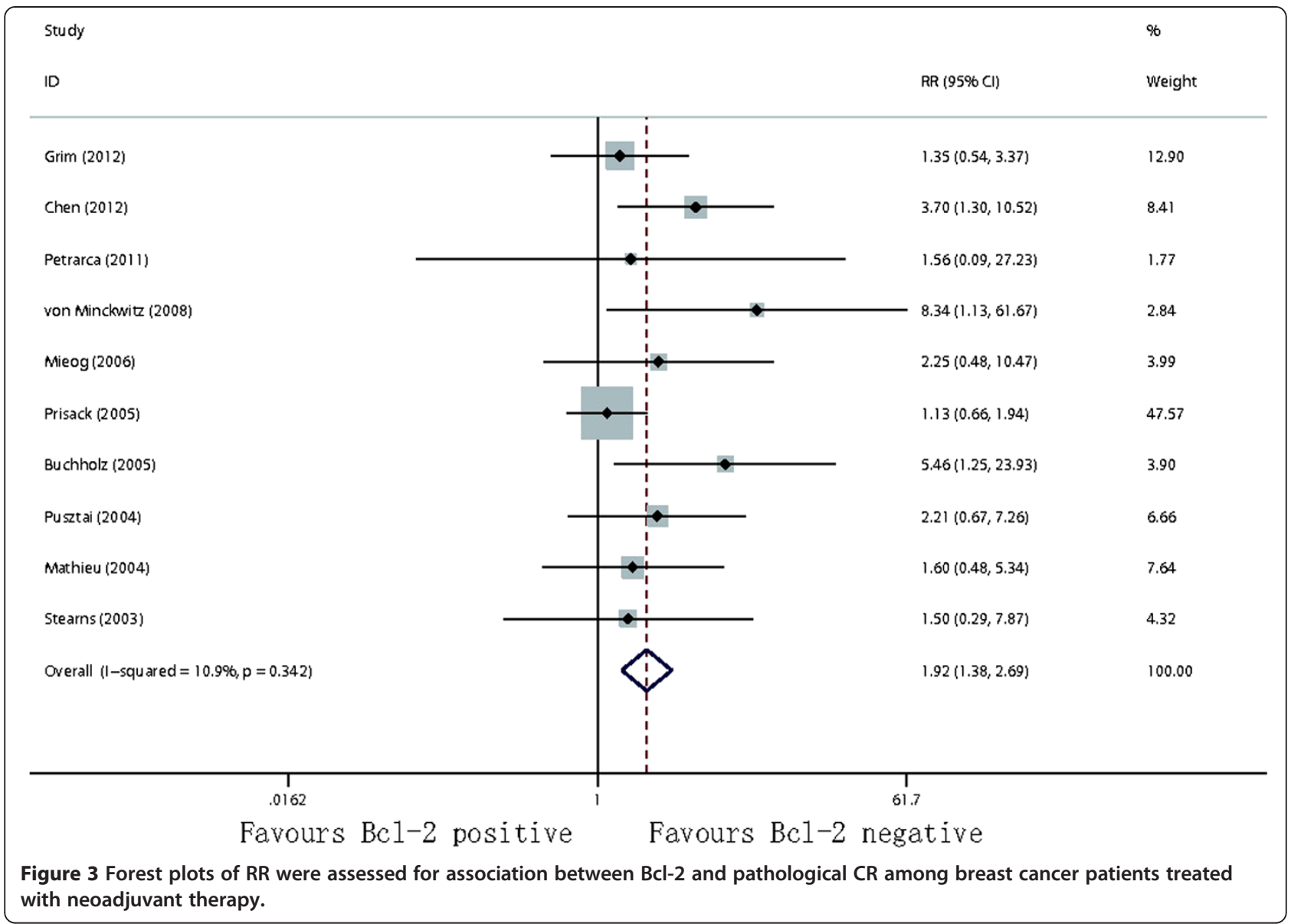

\section{Subgroup analysis}

Among the 23 studies, nineteen used neoadjuvant chemotherapy, one used first-line chemotherapy, one involving neoadjuvant and first-line chemotherapies, and one failed to report, we therefore calculated the associations with favorable responses to neoadjuvant chemotherapy. The results of subgroup analysis were presented in Table 2. Negative Bcl-2 expression was significantly associated with increased total $\mathrm{OR}(\mathrm{RR}=1.19,95 \% \mathrm{CI}=1.04-1.37, \mathrm{p}=$ 0.014), $C R \quad(R R=1.67 ; 95 \% \mathrm{CI}=1.24-2.24 ; \mathrm{p}=0.001)$, pathological $C R(R R=1.92 ; 95 \% C I=1.38-2.69 ; \mathrm{p}<0.001$, Figure 3) among patients treated with neoadjuvant chemotherapy.

Bcl-2 expression has been used to evaluate associations with favorable responses to different treatment regimens of chemotherapy(either by anthracycline- or taxanebased). Among the 23 studies in the chemotherapy subgroup, fifteen used anthracycline-based neoadjuvant chemotherapy and eight used taxane-based neoadjuvant chemotherapy, while five used both anthracyclines and taxanes (Table 2). The results of the anthracycline- and taxane-based neoadjuvant chemotherapies were therefore calculated separately. No study contributed to data on clinical CR in the subgroup analysis. Negative Bcl-2 expression was associated with improved chemo-response in breast cancer patients who received anthracycline-based therapy (total OR: $\mathrm{RR}=1.28,95 \% \mathrm{CI}=1.01-1.43, \mathrm{p}=0.034$, Figure 4; pathological CR: $\mathrm{RR}=1.76,95 \% \mathrm{CI}=1.24-2.51$, $\mathrm{p}=0.002)$. Negative Bcl-2 expression was significantly associated with increased pathological $\mathrm{CR}(\mathrm{RR}=2.11 ; 95 \% \mathrm{CI}=$ 1.14-3.88; $\mathrm{p}=0.017)$ among patients treated with taxanebased therapy, but not with total OR ( $R R=1.37 ; 95 \%$ $\mathrm{CI}=0.88-2.14 ; \mathrm{p}=0.160$ ).

\section{Publication bias}

Begg's funnel plot and Egger's test were used to estimate the publication bias of the included literatures. The shapes of the funnel plots showed no evidence of obvious asymmetry (Figures 5 and 6), and Egger's test indicated the absence of publication bias ( $p>0.05)$. Moreover, sensitivity analysis was carried out to assess the influence of individual study on the summary effects. No individual study dominated this meta-analysis, and the removal of any single study had no significant effect on the overall conclusion (data not shown). 


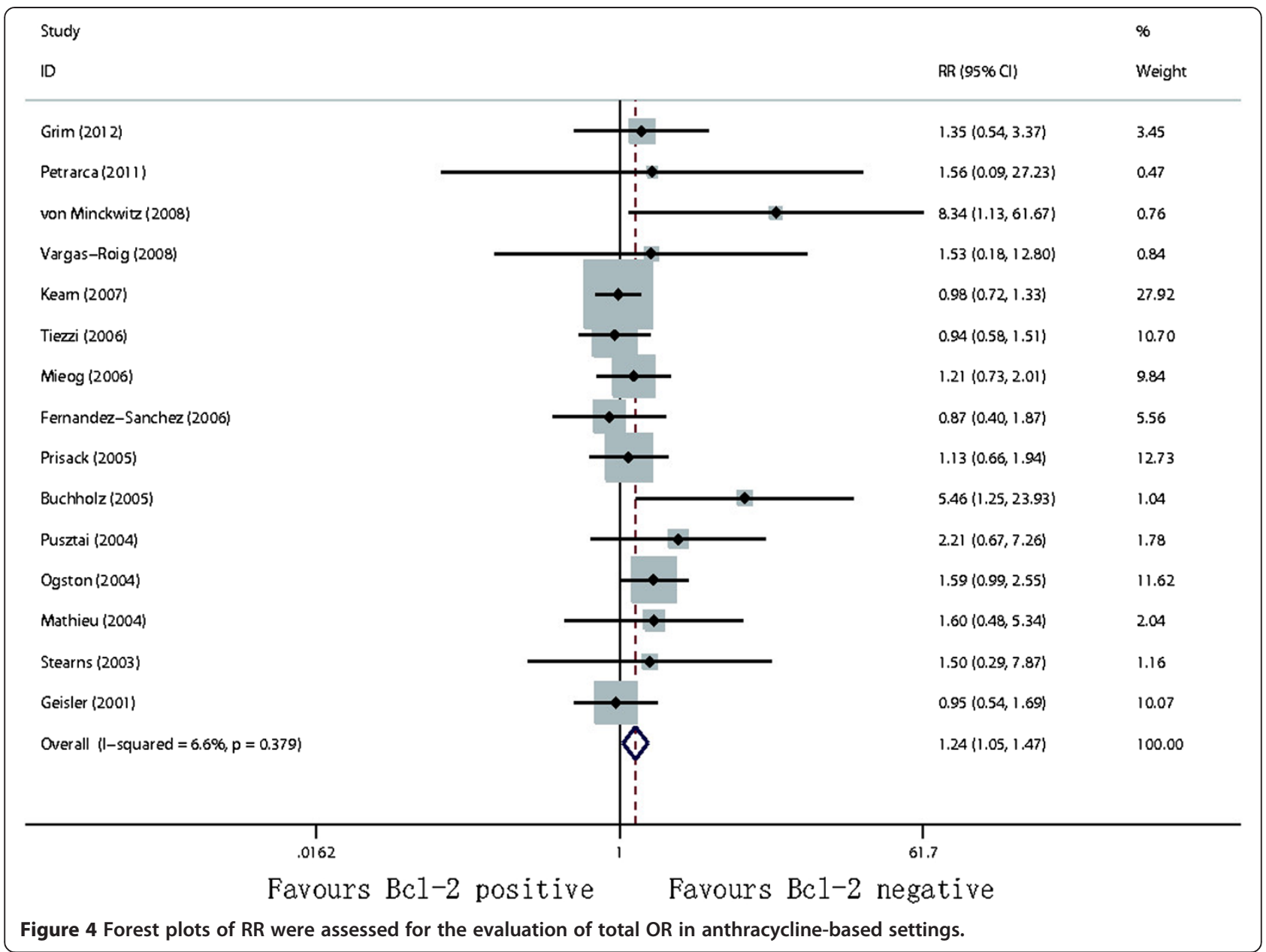

\section{Discussion}

Although there have been many attempts to correlate Bcl2 status with chemosensitivity in breast cancer patients, the results have been controversial. Our systematic review of the literatures shows that negative $\mathrm{Bcl}-2$ expression is a good prognostic factor for predicting sensitivity to chemotherapy of breast cancers. The analysis reveals similar features in different subgroups and clarifies the message of individual studies that are somewhat inconsistent.

In our systematic review with meta-analysis, patients with Bcl-2-negative tumors had significantly better response to chemotherapy than those with $\mathrm{Bcl}$-2-positive tumors. This observation is potentially important. The identification of independent predictive factor allows us to define high-risk patients for whom specific therapy may be designed or to introduce stratification in randomized trials. Furthermore, identifying and validating a predictive biomarker is of more than purely scientific interest because clinical $\mathrm{Bcl}-2$ inhibition is now a practicable clinical approach. Recently, Abbott Laboratories has two drugs in clinical trials that directly target Bcl-2, ABT-263, and ABT-199 [35-37].
Interestingly, we noticed that patients with Bcl-2negative tumors were more likely to achieve a complete remission after neoadjuvant chemotherapy. Multiple clinical trials have shown that patients who achieved a pathological CR after neoadjuvant chemotherapy were associated with improved survival. Intensive researches have thus been focused on identification of "predictive markers" of chemotherapy sensitivity, especially those producing pathological CR [38]. Our results indicated that $\mathrm{Bcl}-2$ expression could potentially help to stratify patients in neoadjuvant chemotherapy.

Notably, we found the correlation between Bcl-2 expression and the response to anthracycline-based chemotherapy. It is important to mention that Vo TT et al. found that Bcl-2 MOLM13 partial knockdown was associated with increased death by topoisomerase II inhibitors (etoposide, daunorubicin, and mitoxantrone) in proportion to the quality of the knockdown [7].

A combination of the analysis of $\mathrm{Bcl}-2$ expression and perhaps other variables (e.g., HER-2, hormone receptor, tumor size and histological subtype) may make it 


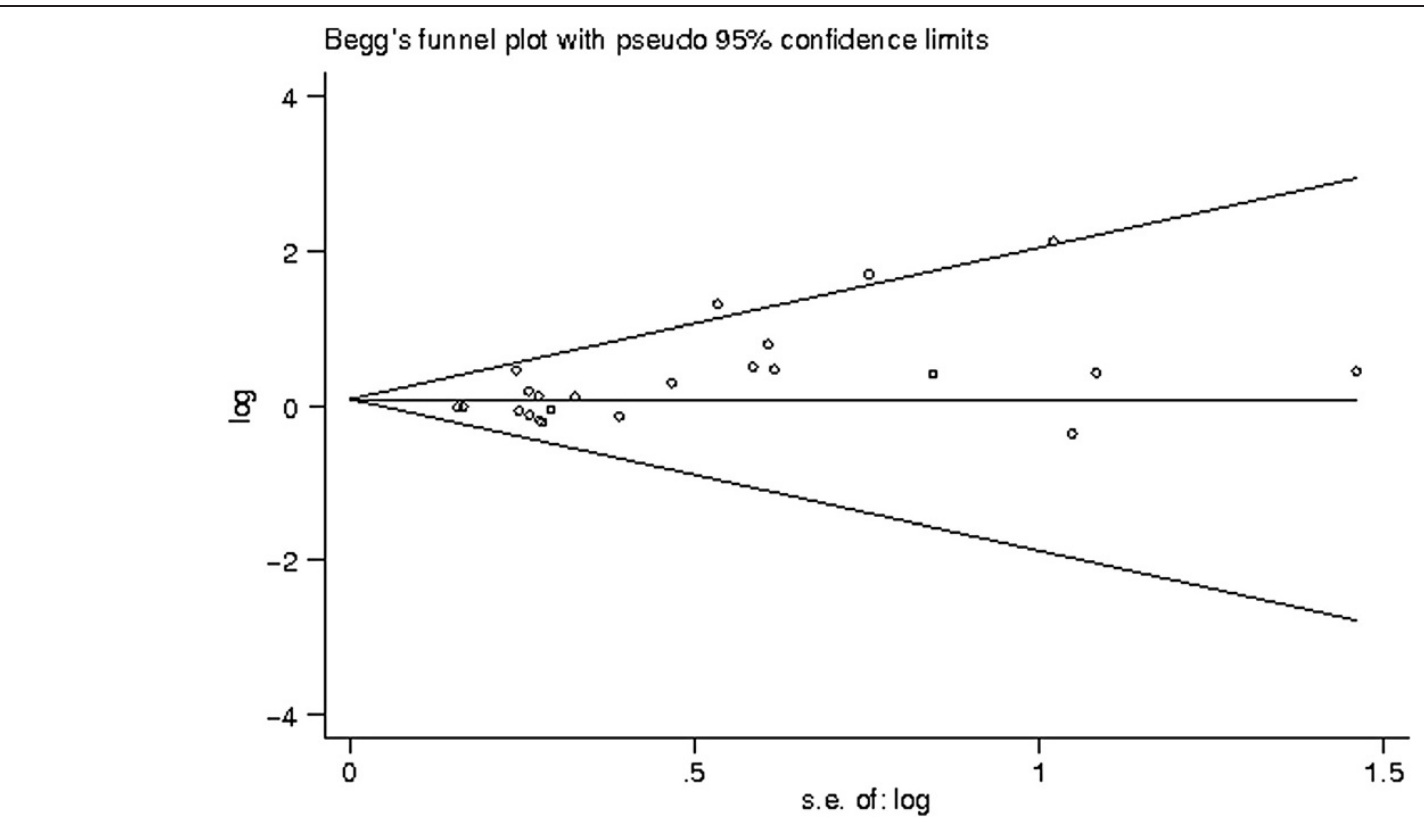

Figure 5 The funnel plot shows that there was no obvious indication of publication bias for the outcome of total OR.

possible, to stratify chemotherapy sensitive subgroup of patients with advanced breast cancer.

The decision to perform the meta-analysis was based on a prior methodological assessment of the publications. We have used a methodology similar to previous systematic reviews reported by our group on the treatment of breast cancer [8] and rectal cancer after an adaptation to biological predictive factors such as p53 [39]. By comparing the scores of the studies where $\mathrm{Bcl}-2$ was a significant predictive factor and those where it was not, we could identify differences, suggesting biases induced by trial methodology. Nevertheless, our approach does not eliminate all potential biases. First, the meta-analysis may have been influenced by publication bias, we limited the search to studies written in English, and we did not search conference proceedings and abstract books, which may have introduced publication bias to this meta-analysis. We tried to identify all relevant data and retrieve additional

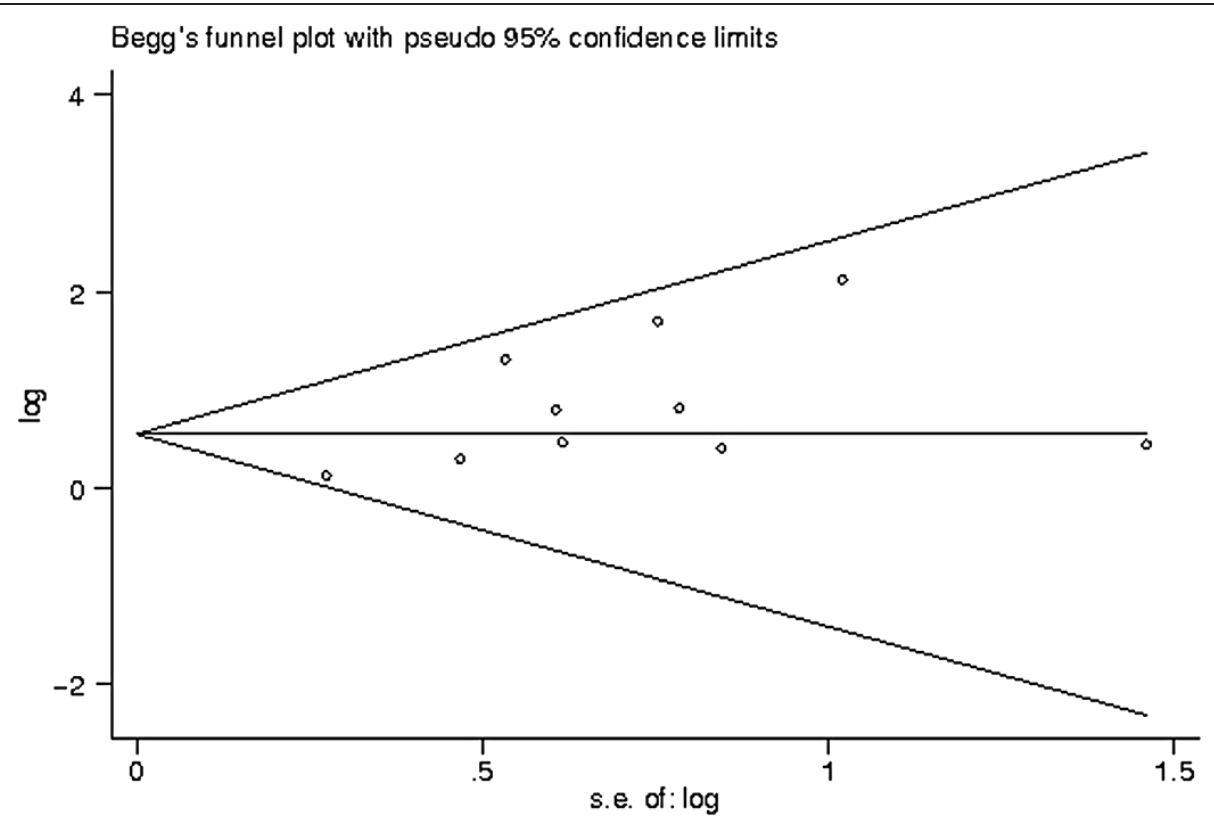

Figure 6 The funnel plot shows that there was no obvious indication of publication bias for the outcome of pathological CR among breast cancer patients treated with neoadjuvant therapy. 
unpublished information, some missing data were, however, unavoidable. Second, the techniques used to identify overexpression of Bcl-2 status can also be a potential source of bias. The IHC used to reveal the $\mathrm{Bcl}-2$ protein is not always performed with the same antibody. Moreover, the cutoff in the number of positive cells defining a tumour with $\mathrm{Bcl}-2$ overexpression often varies according to the investigators, which may lead to biased conclusions. Third, although we made considerable efforts to standardize definitions, some variability in definitions of methods, measurements, and outcomes among studies was inevitable. Fourth, our analysis was observational in nature, and we therefore can't exclude confounding as a potential explanation of the observed results. Despite these limitations, this meta-analysis had several strengths. First, a substantial number of cases were pooled from different studies, and 2,467 subjects represents a sizeable number to significantly increase the statistical power of the analysis. Secondly, no publication biases were detected, indicating that the pooled results may be unbiased.

This study is the first meta-analysis to assess the use of Bcl-2 expression for predicting the chemo-sensitivity of breast cancer patients. Our data support Bcl-2 expression as a useful predictive factor for assessing treatment response to chemotherapy in breast cancer patients. However, future properly designed prospective studies with large sample sizes and an appropriate statistical methodology including multivariate analysis are required to confirm our findings. Moreover, the interaction of this marker with other markers such as HER-2, hormone receptor, tumor size and histological subtype remains unknown and should be a matter for further investigation.

\section{Abbreviations}

Cl: Confidence interval; IHC: Immunohistochemistry; OS: Overall survival; RR: Relative risk; OR: Objective response; CR: Complete response.

\section{Competing interests}

The authors declare that they have no competing interests.

\section{Authors' contributions}

$D Y, M-B C, P-H L$ contributed to the conception and design of the study, the analysis and interpretation of data, the revision of the article as well as final approval of the version to be submitted. LY, C-YL and L-QW. participated in the design of the study, performed the statistical analysis, searched and selected the trials, drafted and revised the article. All authors read and approved the final version of the manuscript.

\section{Funding}

This work was supported by the Natural Science Foundation of Jiangsu Province (No. BK2010160, BK2011374) and the National Natural Science Foundation (No.81108676, 81101801). The funders had no role in study design, data collection and analysis, decision to publish, or preparation of the manuscript.

\section{Author details}

'Department of General Surgery, Kunshan First People's Hospital Affiliated to Jiangsu University, 91 Qianjin Road, Kunshan, Jiangsu Province 215300, China. ${ }^{2}$ Department of Medical Oncology, Kunshan First People's Hospital Affiliated to Jiangsu University, 91 Qianjin Road, Kunshan, Jiangsu Province 215300, China. ${ }^{3}$ Department of Breast Surgery, The Third Affiliated Hospital of
Soochow University, 185 Juqian Street, Changzhou, Jiangsu Province 213000, China. ${ }^{4}$ Department of Medical Oncology, Wuxi People's Hospital affiliated to Nanjing Medical University, 299 Qingyang Road, Wuxi City, Jiangsu Province 214023, China.

Received: 1 October 2013 Accepted: 10 December 2013 Published: 27 December 2013

\section{References}

1. Sekine I, Shimizu C, Nishio K, Saijo N, Tamura T: A literature review of molecular markers predictive of clinical response to cytotoxic chemotherapy in patients with breast cancer. Int J Clin Oncol 2009, 14(2):112-119.

2. Ni Chonghaile T, Sarosiek KA, Vo TT, Ryan JA, Tammareddi A, Moore Vdel G, Deng J, Anderson KC, Richardson P, Tai YT, et al: Pretreatment mitochondrial priming correlates with clinical response to cytotoxic chemotherapy. Science 2011, 334(6059):1129-1133.

3. Brunelle JK, Letai $\mathrm{A}$ : Control of mitochondrial apoptosis by the $\mathrm{BCl}-2$ family. J Cell Sci 2009, 122(Pt 4):437-441.

4. Oltvai ZN, Milliman CL, Korsmeyer SJ: Bcl-2 heterodimerizes in vivo with a conserved homolog, Bax, that accelerates programmed cell death. Cell 1993, 74(4):609-619.

5. Thomadaki H, Scorilas A: Molecular profile of the BCL2 family of the apoptosis related genes in breast cancer cells after treatment with cytotoxic/cytostatic drugs. Connect Tissue Res 2008, 49(3):261-264.

6. Davis JM, Navolanic PM, Weinstein-Oppenheimer CR, Steelman LS, Hu W, Konopleva M, Blagosklonny MV, McCubrey JA: Raf-1 and Bcl-2 induce distinct and common pathways that contribute to breast cancer drug resistance. Clin Cancer Res 2003, 9(3):1161-1170.

7. Vo TT, Ryan J, Carrasco R, Neuberg D, Rossi DJ, Stone RM, Deangelo DJ, Frattini MG, Letai A: Relative mitochondrial priming of myeloblasts and normal HSCs determines chemotherapeutic success in AML. Cell 2012, 151(2):344-355.

8. Li JY, Li YY, Jin W, Yang Q, Shao ZM, Tian XS: ABT-737 reverses the acquired radioresistance of breast cancer cells by targeting $\mathrm{Bcl}-2$ and Bcl-xL. J Exp Clin Cancer Res 2012, 31:102.

9. Miller $A B$, Hoogstraten $B$, Staquet $M$, Winkler $A$ : Reporting results of cancer treatment. Cancer 1981, 47(1):207-214.

10. Therasse P, Arbuck SG, Eisenhauer EA, Wanders J, Kaplan RS, Rubinstein L, Verweij J, Van Glabbeke M, van Oosterom AT, Christian MC, et al: New guidelines to evaluate the response to treatment in solid tumors. European Organization for Research and Treatment of Cancer, National Cancer Institute of the United States, National Cancer Institute of Canada. J Natl Cancer Inst 2000, 92(3):205-216.

11. Higgins JP, Thompson SG, Deeks JJ, Altman DG: Measuring inconsistency in meta-analyses. BMJ 2003, 327(7414):557-560.

12. Grim J, Jandik P, Slanska I, Dolezalova-Brcakova E, Fuksa L, Ryska A, Knizek J, Petera J, Micuda S, Hornychova H: Low expression of NQO1 predicts pathological complete response to neoadjuvant chemotherapy in breast cancer patients treated with TAC regimen. Folia Biol (Praha) 2012, 58(5):185-192.

13. Chen $X$, Wu J, Lu H, Huang O, Shen K: Measuring beta-tubulin III, BCl-2, and ERCC1 improves pathological complete remission predictive accuracy in breast cancer. Cancer Sci 2012, 103(2):262-268.

14. Petrarca CR, Brunetto AT, Duval V, Brondani A, Carvalho GP, Garicochea B: Survivin as a predictive biomarker of complete pathologic response to neoadjuvant chemotherapy in patients with stage II and stage III breast cancer. Clin Breast Cancer 2011, 11(2):129-134.

15. von Minckwitz G, Sinn HP, Raab G, Loibl S, Blohmer JU, Eidtmann H, Hilfrich J, Merkle E, Jackisch C, Costa SD, et al: Clinical response after two cycles compared to HER2, Ki-67, p53, and bcl-2 in independently predicting a pathological complete response after preoperative chemotherapy in patients with operable carcinoma of the breast. Breast Cancer Res 2008, 10(2):R30.

16. Vargas-Roig LM, Cuello-Carrion FD, Fernandez-Escobar N, Daguerre P, Leuzzi M, Ibarra J, Gago FE, Nadin SB, Ciocca DR: Prognostic value of Bcl-2 in breast cancer patients treated with neoadjuvant anthracycline based chemotherapy. Mol Oncol 2008, 2(1):102-111.

17. Keam B, Im SA, Kim HJ, Oh DY, Kim JH, Lee SH, Chie EK, Han W, Kim DW, Moon WK, et al: Prognostic impact of clinicopathologic parameters in stage II/III breast cancer treated with neoadjuvant docetaxel and 
doxorubicin chemotherapy: paradoxical features of the triple negative breast cancer. BMC Cancer 2007, 7:203.

18. Tiezzi DG, De Andrade JM, Reis FJ C d, Marana HR, Ribeiro-Silva A, Tiezzi MG, Pereira AP: Apoptosis induced by neoadjuvant chemotherapy in breast cancer. Pathology 2006, 38(1):21-27.

19. Noguchi S: Predictive factors for response to docetaxel in human breast cancers. Cancer Sci 2006, 97(9):813-820.

20. Cooperating Investigators of the E, Mieog JS, van der Hage JA, van de Vijuer $\mathrm{MJ}$, van de Velde CJ: Tumour response to preoperative anthracycline-based chemotherapy in operable breast cancer: the predictive role of $\mathrm{p} 53$ expression. Eur J Cancer 2006, 42(10):1369-1379.

21. Fernandez-Sanchez M, Gamboa-Dominguez A, Uribe N, Garcia-Ulloa AC, Flores-Estrada D, Candelaria M, Arrieta O: Clinical and pathological predictors of the response to neoadjuvant anthracycline chemotherapy in locally advanced breast cancer. Med Oncol 2006, 23(2):171-183.

22. Prisack HB, Karreman C, Modlich O, Audretsch W, Danae M, Rezai M, Bojar H: Predictive biological markers for response of invasive breast cancer to anthracycline/cyclophosphamide-based primary (radio-)chemotherapy. Anticancer Res 2005, 25(6C):4615-4621.

23. Kim SJ, Miyoshi Y, Taguchi T, Tamaki Y, Nakamura H, Yodoi J, Kato K, Noguchi S: High thioredoxin expression is associated with resistance to docetaxel in primary breast cancer. Clin Cancer Res 2005, 11(23):8425-8430.

24. Buchholz TA, Garg AK, Chakravarti N, Aggarwal BB, Esteva FJ, Kuerer HM, Singletary SE, Hortobagyi GN, Pusztai L, Cristofanilli M, et al: The nuclear transcription factor kappaB/bcl-2 pathway correlates with pathologic complete response to doxorubicin-based neoadjuvant chemotherapy in human breast cancer. Clin Cancer Res 2005, 11(23):8398-8402.

25. Pusztai L, Krishnamurti S, Perez Cardona J, Sneige N, Esteva FJ, Volchenok M, Breitenfelder P, Kau SW, Takayama S, Krajewski S, et al: Expression of BAG-1 and BCL-2 proteins before and after neoadjuvant chemotherapy of locally advanced breast cancer. Cancer Invest 2004, 22(2):248-256.

26. Ogston KN, Miller ID, Schofield AC, Spyrantis A, Pavlidou E, Sarkar TK, Hutcheon AW, Payne S, Heys SD: Can patients' likelihood of benefiting from primary chemotherapy for breast cancer be predicted before commencement of treatment? Breast Cancer Res Treat 2004, 86(2):181-189.

27. Mathieu MC, Rouzier R, Llombart-Cussac A, Sideris L, Koscielny S, Travagli JP, Contesso G, Delaloge S, Spielmann M: The poor responsiveness of infiltrating lobular breast carcinomas to neoadjuvant chemotherapy can be explained by their biological profile. Eur J Cancer 2004, 40(3):342-351.

28. Stearns V, Singh B, Tsangaris T, Crawford JG, Novielli A, Ellis MJ, Isaacs C, Pennanen M, Tibery C, Farhad A, et al: A prospective randomized pilot study to evaluate predictors of response in serial core biopsies to single agent neoadjuvant doxorubicin or paclitaxel for patients with locally advanced breast cancer. Clin Cancer Res 2003, 9(1):124-133.

29. Geisler S, Lonning PE, Aas T, Johnsen H, Fluge O, Haugen DF, Lillehaug JR, Akslen LA, Borresen-Dale AL: Influence of TP53 gene alterations and c-erbB-2 expression on the response to treatment with doxorubicin in locally advanced breast cancer. Cancer Res 2001, 61(6):2505-2512.

30. Pernick NL, Biernat L, Du W, Visscher DW: Clinicopathologic Analysis of Fas, Fas Ligand, and Other Biomarkers in Locally Advanced Breast Carcinoma. Breast J 2000, 6(4):233-241.

31. Bottini A, Berruti A, Bersiga A, Brizzi MP, Brunelli A, Gorzegno G, DiMarco B, Aguggini S, Bolsi G, Cirillo F, et al: p53 but not bcl-2 immunostaining is predictive of poor clinical complete response to primary chemotherapy in breast cancer patients. Clin Cancer Res 2000, 6(7):2751-2758.

32. Nole F, Minchella I, Colleoni M, Orvieto E, Munzone E, de Braud F, Peruzzotti G, Martinelli G, Zampino MG, Catania C, et al: Primary chemotherapy in operable breast cancer with favorable prognostic factors: a pilot study evaluating the efficacy of a regimen with a low subjective toxic burden containing vinorelbine, 5 -fluorouracil and folinic acid (FLN). Ann Oncol 1999, 10(8):993-996.

33. Colleoni M, Orvieto E, Nole F, Orlando L, Minchella I, Viale G, Peruzzotti G, Robertson C, Noberasco C, Galimberti V, et al: Prediction of response to primary chemotherapy for operable breast cancer. Eur J Cancer 1999, 35(4):574-579.

34. Makris A, Powles TJ, Dowsett M, Osborne CK, Trott PA, Fernando IN, Ashley SE, Ormerod MG, Titley JC, Gregory RK, et al: Prediction of response to neoadjuvant chemoendocrine therapy in primary breast carcinomas. Clin Cancer Res 1997, 3(4):593-600.

35. Roberts AW, Seymour JF, Brown JR, Wierda WG, Kipps TJ, Khaw SL, Carney DA, He SZ, Huang DC, Xiong H, et al: Substantial susceptibility of chronic lymphocytic leukemia to BCL2 inhibition: results of a phase I study of navitoclax in patients with relapsed or refractory disease. J Clin Oncol 2012, 30(5):488-496.

36. Wilson WH, O'Connor OA, Czuczman MS, LaCasce AS, Gerecitano JF, Leonard JP, Tulpule A, Dunleavy K, Xiong H, Chiu YL, et al: Navitoclax, a targeted high-affinity inhibitor of BCL-2, in lymphoid malignancies: a phase 1 dose-escalation study of safety, pharmacokinetics, pharmacodynamics, and antitumour activity. Lancet Oncol 2010, 11(12):1149-1159.

37. Tse C, Shoemaker AR, Adickes J, Anderson MG, Chen J, Jin S, Johnson EF, Marsh KC, Mitten MJ, Nimmer P, et al: ABT-263: a potent and orally bioavailable Bcl-2 family inhibitor. Cancer Res 2008, 68(9):3421-3428.

38. Tewari M, Pradhan S, Singh U, Singh TB, Shukla HS: Assessment of predictive markers of response to neoadjuvant chemotherapy in breast cancer. Asian J Surg 2010, 33(4):157-167.

39. Chen MB, Wu XY, Yu R, Li C, Wang LQ, Shen W, Lu PH: P53 status as a predictive biomarker for patients receiving neoadjuvant radiation-based treatment: a meta-analysis in rectal cancer. PLoS One 2012, 7(9):e45388.

doi:10.1186/1756-9966-32-105

Cite this article as: Yang et al:: $\mathrm{Bcl}-2$ expression predicts sensitivity to chemotherapy in breast cancer: a systematic review and meta-analysis. Journal of Experimental \& Clinical Cancer Research 2013 32:105.

\section{Submit your next manuscript to BioMed Central and take full advantage of:}

- Convenient online submission

- Thorough peer review

- No space constraints or color figure charges

- Immediate publication on acceptance

- Inclusion in PubMed, CAS, Scopus and Google Scholar

- Research which is freely available for redistribution 